\title{
Relationships between Sleep Patterns, Health Risk Behaviors, and Health Outcomes among School-Based Population of Adolescents: A Panel Analysis of the Korean Children and Youth Panel Survey
}

\author{
Jinseok Kim ${ }^{1}$, Jin-Won Noh ${ }^{2,3}$, Ahraemi Kim ${ }^{1}$ and Young Dae Kwon ${ }^{4, *}$ \\ 1 Department of Social Welfare, Seoul Women's University, Seoul 01797, Korea \\ 2 Department of Healthcare Management, Eulji University, Seongnam 13135, Korea \\ 3 Global Health Unit, Department of Health Sciences, University Medical Centre Groningen, \\ University of Groningen, Groningen 9713 GZ, The Netherlands \\ 4 Department of Humanities and Social Medicine, College of Medicine and Catholic Institute for Healthcare \\ Management, The Catholic University of Korea, Seoul 06591, Korea \\ * Correspondence: healthcare@catholic.ac.kr; Tel.: +82-2-2258-8251; Fax: +82-2-2258-8257
}

Received: 30 May 2019; Accepted: 25 June 2019; Published: 27 June 2019

check for updates

\begin{abstract}
Sleep patterns among adolescents are related to health outcomes and health risk behaviors. This study aimed to describe sleep patterns of Korean adolescents and to find the association between sleep patterns and health risk behaviors and health outcomes. Using the junior high school students' panel data ( $n=2351,12-15$ years old) from the Korean Children and Youth Panel Survey, this study described the sleep patterns operationalized as rising time, bedtime, and sleep duration both on weekdays and weekends. The relationships of sleep patterns with health outcomes and/or health risk behaviors were tested using mixed effect linear regression for continuous health variables and using mixed effect logit regression for binary health variables. Obesity status, the number of chronic symptoms, self-rated health status, smoking, and alcohol consumption were associated with rising time on weekdays after controlling for gender, living area, and housing type. The same set of variables except for the number of chronic symptoms were associated with bedtime during the weekdays. Sleep duration during the weekdays was associated with obesity status, smoking, and alcohol consumption. Similar patterns of association between sleep pattern variables during the weekends and health-related outcome variables were found, but were less obvious than those for weekdays. Significant relationships between sleep patterns and various health-related variables were found among adolescents in Korea. The results from this study indicate that helping adolescents change their sleeping times as necessary to ensure adequate sleep should be considered important in diminishing health risk behaviors and promoting positive health outcomes.
\end{abstract}

Keywords: sleep patterns; health risk behaviors; health outcomes; adolescents

\section{Introduction}

Sleep plays a vital role in good health and well-being. Appropriate, quality sleep helps to protect both physical and mental health and increases quality of life and safety [1]. Especially, adolescents have a physiological need for more sleep [2], and inadequate sleep quantity and quality are linked to significant problems in several health aspects including obesity [3], self-rated health (SRH) [3], smoking [4], and alcohol consumption [4]. In addition, inadequate sleep causes multiple problems in the school setting, where both suboptimal sleep duration and sleep disturbance are associated with reduced academic functioning, including attentional difficulties and increased absences [5-7]. 
Most adolescents experience dramatic changes in sleep and wake patterns [8], including a decrease in sleep duration [9-11], a delay in the timing of sleep, and spontaneous morning arousal [2,12-18], and an increasingly large discrepancy between weekday and weekend sleep patterns [5,18-20]. Those changes in sleep patterns are due to the psychosocial pressures of homework, sports, jobs, social activities, and decreases in parental control over bedtime. These pressures combine to reduce the amount of time adolescents spend on sleeping [13,21]. Korean adolescents experience greater inadequate sleep problems than their peers in the West due to a special emphasis on education and obedience to parental aspirations for excessive study based on strong Confucianism traditions [22].

Sleep patterns in adolescence have been consistently shown to be associated with health outcomes [23-26]. Sleep deprivation caused by poor sleep patterns has the greatest negative effects on the control of behavior, emotion, and attention [27]. Thus, sleep patterns have relationships with health behaviors, like cigarette use, alcohol use, low participation in physical activity, and suicide contemplation [28]. However, only a few studies have been conducted on the association between sleep patterns and health outcomes [23,28,29] or health behaviors [4,28]. Most of these studies focused on sleep duration and not on various aspects of sleep patterns such as rising time and bedtime. The purpose of this study was to describe the sleep patterns and to examine the relationships between sleep patterns, health risk behaviors, and health outcomes among Korean adolescents using nationally representative longitudinal data that indicate the importance of healthy sleep patterns for reducing health risk behaviors and producing better health outcomes.

\section{Methods}

\subsection{Data and Subjects}

This study utilized data from the Korean Children and Youth Panel Survey (KCYPS), a nationally representative study of Korean children and youths. The KCYPS, aiming to investigate various aspects of children's and youths' growth and development, started to collect data from three different panels of first and fourth grade elementary school students and first grade junior high school students in 2010 ( $n=7071$ ). This same group of students was followed annually until 2016. The KCYPS employed a multi-stage stratified cluster sampling method with schools as the primary sampling unit. The schools were selected using a probability proportional to size sampling method. This analysis used the junior high school student panel $(n=2351)$ that included participant developmental stages from first year of junior high school up to one year after high school graduation. The participants' ages at the first wave ranged from 12 to 15 years old. This study was approved by the Institutional Review Board of the Seoul Women's University (IRB-2018-46) with a waiver for informed consent because the data were obtained from a public data depository which is freely accessible online at http://archive.nypi.re.kr/modedg/contentsView.do?ucont_id=CTX000029\&menu_nix=qZc474Ak.

\subsection{Variables and Measurement}

Three indicators measuring sleep patterns of adolescents were utilized in this analysis. Bedtime and wake-up time were ascertained using the question "What time do you usually go to bed and get up?", which was asked for weekdays and for weekend days separately. Sleep duration during weekdays and weekend days were calculated using the answers for the bedtime and wake-up time questions.

Several health outcomes and health risk behaviors such as SRH, number of chronic symptoms, obesity, smoking, and alcohol consumption were included in this analysis. SRH was measured using a 4-point Likert scale ( $1=$ "very unhealthy"; $4=$ "very healthy"). Respondents were asked about any chronic symptoms of asthma, rhinitis, atopic dermatitis, heart disease, diabetes, or other chronic disease experiences during the last year. The number of chronic symptoms experienced during the last year was counted and used in the analysis. Obesity status was measured by calculating the body mass index (BMI) using respondent self-reported height and weight. Finally, health risk behaviors, such as smoking and alcohol consumption during the last year, were measured using respondent 
self-reports of such behaviors. Gender, regional area, and type of housing were included as control variables. Gender was measured using a dichotomous variable (male $=1$, female $=0$ ) and area was also dummy-coded (urban $=1$, non-urban $=0$ ). Type of housing had three dummy-coded categories $(1=$ house, 2 = apartment, 3 = others $)$.

\subsection{Statistical Analysis}

In order to provide sample characteristics, a set of descriptive analyses were conducted. The relationships of sleep patterns with health outcomes and/or health risk behaviors were tested using mixed effect linear regression for continuous health variables and using mixed effect logit regression for binary health variables. The mixed effect regression models were considered appropriate for analysis of panel data structure such as the KCYPS [30]. Stata 15 (StataCorp LP, College Station, TX, USA) was used to manipulate the data and calculate the model parameters.

\section{Results}

The characteristics of the sample are presented in Table 1. Half of the participants in the sample were female. A majority of participants (85.7\%) lived in urban areas. In terms of housing types, $59.1 \%$ lived in apartments and $20.6 \%$ lived in houses.

The proportion of obese adolescents increased from $8.4 \%$ in Wave 2 to $16.5 \%$ in Wave 6 . Female adolescents were less likely to be obese than male adolescents across the study period. Smoking and alcohol consumption behaviors among the adolescents increased over time. In Wave 2, 6.2\% and 4.7\% of the respondents were smoking and drinking alcohol, respectively, while $11.2 \%$ and $27.3 \%$ were doing the same in Wave 6, respectively. Again, females were less likely to smoke or drink alcohol than male counterparts throughout the study period. The number of chronic symptoms was asked only in Wave 1 and 4 . In both the waves, the adolescents reported less than one chronic symptom with higher number in Wave 1 (mean 0.64, SD 0.78) than in Wave 4 (mean 0.59, SD 0.83). SRH score did not show a consistent pattern of change over time, but male adolescents seemed to report higher scores than female respondents.

Table 1 also presented the overall patterns of sleep variables over the study period. The respondents reported from 6.12 (Wave 5) to $7.90 \mathrm{~h}$ (Wave 1) of sleep duration (weekdays) during the study period. Females appeared to sleep less than male counterparts throughout the study period. Overall, the respondents spend less amount of time on sleeping as they got older. Respondents' bedtime was getting later as they grew up, but rising time did not change as much as the bedtime did (Table 1).

Table 2 summarizes the results of the mixed effects regression analyses of health outcomes and health risk behaviors with sleep duration, bedtime, and wake-up time as predictors after controlling for gender, regional area, and type of housing. Results showed that the number of chronic symptoms was negatively associated with wake-up time on weekdays: The earlier adolescents woke up in the morning during weekdays, the less chronic symptoms were experienced during the last year. The analyses also showed that adolescents going to bed earlier on both weekdays and weekends tended to report higher SRH scores. Additionally, early-rising adolescents tended to report higher SRH scores. Obesity risk was negatively associated with sleep duration both on weekdays and weekends and positively with bedtime and wake-up times both on weekdays and weekends. Bedtime and wake-up times during both weekdays and weekends were positively associated with adolescents' likelihood of reporting smoking and alcohol consumption behaviors during the last year. Also, sleep duration on both weekdays and weekends was negatively associated with the likelihood of adolescents' self-reported alcohol consumption (Table 2). 
Table 1. Sample description.

\begin{tabular}{|c|c|c|c|c|c|c|c|c|c|c|c|c|c|}
\hline \multirow{2}{*}{ Variable } & \multirow{2}{*}{ Category } & \multicolumn{2}{|c|}{ Wave 1} & \multicolumn{2}{|c|}{ Wave 2} & \multicolumn{2}{|c|}{ Wave 3} & \multicolumn{2}{|c|}{ Wave 4} & \multicolumn{2}{|c|}{ Wave 5} & \multicolumn{2}{|c|}{ Wave 6} \\
\hline & & 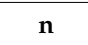 & $\%$ & $\mathbf{N}$ & $\%$ & $\mathrm{n}$ & $\%$ & $n$ & $\%$ & $\mathbf{n}$ & $\%$ & $\mathrm{n}$ & $\%$ \\
\hline Gender: & Female & 1175 & 50.0 & & & & & & & & & & \\
\hline Area & Urban & 2014 & 85.7 & & & & & & & & & & \\
\hline \multirow[t]{3}{*}{ Housing type } & House & 482 & 20.6 & & & & & & & & & & \\
\hline & Apartment & 1385 & 59.1 & & & & & & & & & & \\
\hline & Other & 477 & 20.4 & & & & & & & & & & \\
\hline \multirow[t]{3}{*}{ Obesity } & Total & & & 190 & 8.4 & 185 & 8.2 & 224 & 10.7 & 263 & 12.7 & 337 & 16.5 \\
\hline & Female & & & 64 & 5.7 & 65 & 5.9 & 80 & 7.8 & 98 & 9.7 & 133 & 13.2 \\
\hline & Male & & & 126 & 11.0 & 120 & 10.5 & 144 & 13.4 & 165 & 15.5 & 204 & 19.6 \\
\hline \multirow[t]{3}{*}{ Smoking } & Total & & & 141 & 6.2 & 147 & 6.5 & 189 & 9.0 & 229 & 11 & 231 & 11.2 \\
\hline & Female & & & 38 & 3.4 & 26 & 2.3 & 30 & 2.9 & 26 & 2.5 & 28 & 2.8 \\
\hline & Male & & & 103 & 8.9 & 121 & 10.6 & 159 & 14.8 & 203 & 19.0 & 203 & 19.5 \\
\hline \multirow[t]{5}{*}{ Alcohol drinking } & Total & & & 107 & 4.7 & 160 & 7.1 & 272 & 12.9 & 444 & 21.2 & 562 & 27.3 \\
\hline & Female & & & 54 & 4.8 & 61 & 5.5 & 77 & 7.5 & 131 & 12.8 & 161 & 15.9 \\
\hline & Male & & & 53 & 4.6 & 99 & 8.7 & 195 & 18.1 & 313 & 29.3 & 401 & 38.5 \\
\hline & & Mean & SD & Mean & SD & Mean & SD & Mean & SD & Mean & SD & Mean & SD \\
\hline & Total & 0.64 & 0.78 & & & & & 0.59 & 0.83 & & & & \\
\hline \multirow[t]{3}{*}{ Number of chronic symptoms } & Feale & 0.59 & 0.76 & & & & & 0.57 & 0.84 & & & & \\
\hline & Male & 0.68 & 0.80 & & & & & 0.61 & 0.82 & & & & \\
\hline & Total & 3.16 & 0.61 & 3.20 & 0.62 & 3.21 & 0.63 & 3.24 & 0.58 & 3.13 & 0.58 & 3.23 & 0.59 \\
\hline \multirow{3}{*}{ Self-rated health } & Female & 3.15 & 0.57 & 3.20 & 0.59 & 3.20 & 0.61 & 3.18 & 0.55 & 3.08 & 0.54 & 3.18 & 0.57 \\
\hline & Male & 3.17 & 0.64 & 3.20 & 0.65 & 3.23 & 0.65 & 3.29 & 0.60 & 3.18 & 0.62 & 3.29 & 0.62 \\
\hline & Total & 7.90 & 0.98 & 7.67 & 0.96 & 7.36 & 1.01 & 6.31 & 1.10 & 6.12 & 1.12 & 6.31 & \\
\hline \multirow[t]{3}{*}{ Sleep duration during weekdays (h) } & Female & 7.75 & 0.96 & 7.48 & 0.95 & 7.19 & 1.02 & 6.16 & 1.06 & 6.01 & 1.08 & 6.20 & \\
\hline & Male & 8.05 & 0.98 & 7.86 & 0.94 & 7.52 & 0.97 & 6.46 & 1.11 & 6.22 & 1.15 & 6.43 & \\
\hline & Total & 23.12 & 0.93 & 23.34 & 0.93 & 23.66 & 0.99 & 24.28 & 1.04 & 24.57 & 1.05 & 24.51 & \\
\hline \multirow[t]{3}{*}{ Bedtime during weekdays (h) } & Female & 23.23 & 0.94 & 23.47 & 0.94 & 23.77 & 1.00 & 24.34 & 1.03 & 24.60 & 1.02 & 24.53 & \\
\hline & Male & 23.01 & 0.91 & 23.22 & 0.91 & 23.56 & 0.96 & 24.22 & 1.04 & 24.55 & 1.08 & 24.50 & \\
\hline & Total & 7.02 & 0.48 & 7.01 & 0.48 & 7.02 & 0.51 & 6.59 & 0.51 & 6.69 & 0.56 & 6.83 & \\
\hline \multirow[t]{3}{*}{ Rise time during weekdays (h) } & Female & 6.97 & 0.44 & 6.95 & 0.47 & 6.96 & 0.48 & 6.51 & 0.50 & 6.61 & 0.54 & 6.73 & \\
\hline & Male & 7.07 & 0.51 & 7.07 & 0.48 & 7.08 & 0.53 & 6.68 & 0.50 & 6.76 & 0.57 & 6.93 & \\
\hline & Total & 9.52 & 1.57 & 9.40 & 1.59 & 9.14 & 1.61 & 8.53 & 1.64 & 8.32 & 1.63 & 8.25 & \\
\hline \multirow[t]{3}{*}{ Sleep duration during weekends (h) } & Female & 9.74 & 1.63 & 9.61 & 1.62 & 9.30 & 1.55 & 8.69 & 1.65 & 8.40 & 1.64 & 8.26 & \\
\hline & Male & 9.30 & 1.48 & 9.20 & 1.53 & 8.98 & 1.65 & 8.37 & 1.61 & 8.25 & 1.61 & 8.24 & \\
\hline & Total & 23.76 & 1.17 & 23.90 & 1.19 & 24.35 & 1.29 & 24.86 & 1.28 & 25.10 & 1.25 & 25.17 & \\
\hline \multirow[t]{3}{*}{ Bedtime during weekends (h) } & Female & 23.90 & 1.18 & 24.05 & 1.17 & 24.45 & 1.28 & 24.84 & 1.23 & 25.07 & 1.17 & 25.12 & \\
\hline & Male & 23.63 & 1.15 & 23.75 & 1.19 & 24.25 & 1.29 & 24.88 & 1.34 & 25.12 & 1.32 & 25.22 & \\
\hline & Total & 9.28 & 1.64 & 9.30 & 1.64 & 9.49 & 1.65 & 9.39 & 1.65 & 9.42 & 1.69 & 9.42 & \\
\hline \multirow[t]{2}{*}{ Rise time during weekends (h) } & Female & 9.64 & 1.65 & 9.65 & 1.65 & 9.75 & 1.57 & 9.53 & 1.63 & 9.47 & 1.64 & 9.38 & \\
\hline & Male & 8.92 & 1.55 & 8.96 & 1.55 & 9.23 & 1.69 & 9.26 & 1.66 & 9.37 & 1.74 & 9.46 & \\
\hline
\end{tabular}


Table 2. Mixed effects regression analyses of health outcomes and health risk behaviors with sleep patterns.

\begin{tabular}{|c|c|c|c|c|c|c|}
\hline & \multicolumn{3}{|c|}{ Weekday } & \multicolumn{3}{|c|}{ Weekend } \\
\hline & $\begin{array}{c}\text { Sleep duration } \\
\text { B (SE) }\end{array}$ & $\begin{array}{l}\text { Bedtime } \\
\text { B (SE) }\end{array}$ & $\begin{array}{l}\text { Wake-up time } \\
\text { B (SE) }\end{array}$ & $\begin{array}{l}\text { Sleep duration } \\
\text { B (SE) }\end{array}$ & $\begin{array}{l}\text { Bedtime } \\
\text { B (SE) }\end{array}$ & $\begin{array}{c}\text { Wake-up time } \\
\text { B (SE) }\end{array}$ \\
\hline Obesity & $-0.003^{* * *}(0.001)$ & $0.006^{* * *}(0.001)$ & $0.003^{* * *}(0.001)$ & $-0.002 * * *(0.001)$ & $0.004^{* * *}(0.001)$ & $0.001^{* *}(0.001)$ \\
\hline Smoking (1 year) & $-0.03(0.05)$ & $0.84^{* * *}(0.06)$ & $1.00 * * *(0.07)$ & $-0.03(0.04)$ & $0.73^{* * *}(0.05)$ & $0.52^{* * *}(0.04)$ \\
\hline Alcohol drinking (1 year) & $-0.07 *(0.03)$ & $0.99^{* * *}(0.04)$ & $1.35^{* * *}(0.05)$ & $-0.13^{* * *}(0.02)$ & $0.80^{* * *}(0.03)$ & $0.40 * * *(0.02)$ \\
\hline Number of chronic symptoms & $-0.01(0.01)$ & $-0.01(0.01)$ & $-0.03 *(0.01)$ & $0.01(0.01)$ & $-0.01(0.01)$ & $-0.00(0.01)$ \\
\hline Self-rated health & $0.00(0.01)$ & $-0.02 * *(0.01)$ & $-0.03^{* * *}(0.01)$ & $0.02(0.05)$ & $-0.01 *(0.01)$ & $-0.01(0.05)$ \\
\hline
\end{tabular}

Note: results were controlled for gender, area, and type of housing (i.e., house/apartment/and others). ${ }^{*} p<0.05,{ }^{* *} p<0.01$, ${ }^{* * *} p<0.001$. SE, standard error. 


\section{Discussion}

To our knowledge, this is the first large-sample, nationally representative longitudinal study of adolescents to investigate relationships of diverse sleep patterns, health outcomes, and health risk behaviors. Sleep quality including sufficient sleep, earlier wake-up time, and earlier bedtime is associated with better health outcomes and diminished health risk behaviors [23-26,28,29]. Shorter sleep duration was associated with obesity. These results are consistent with reports that shorter sleep time has contributed to the obesity epidemic [31-35]. Wheaton et al. [35] demonstrated that short sleep duration was linked to unhealthy weight-control behaviors including dieting, fasting, and purging that can lead to being obese. This also can be explained by increased adolescent wake times equating to more opportunities to eat.

Shorter sleep time was positively associated with alcohol consumption [36]. McKnight-Eily et al. [4] found a synergistic effect of short sleep duration and alcohol consumption on school maladjustment, sexual activities, and degraded cognitive abilities. On the other hand, the findings did not show a significant relationship between sleep duration and smoking in contrast to prior studies [4,36,37]. This difference may be due to the low rate of smoking in the sample. In summation, sufficient sleep should be encouraged by enhancing adolescent self-control and parental support. Moreover, children having parents with high health literacy reported significantly longer sleep duration [38]. Thus, parental health literacy may be a key intervention to lengthen the sleep duration in adolescence.

When adolescents go to bed or rise appeared to play a pivotal role in health outcomes and health risk behaviors. Rise time was negatively associated with the number of chronic symptoms. Adolescents going to bed earlier on both weekdays and weekends tended to report higher SRH scores. Earlier bedtime and earlier rise time were linked to higher SRH scores. It is a novel finding that not only total sleep duration, but also bedtime and wake-up time, are related to SRH. Prior research primarily only identified that sleep duration was negatively associated with SRH. This new finding implies the importance of sleep patterns including wake-up and bedtime as well as sleep duration. Goh [39] showed that a 10 p.m. bedtime was less likely to be associated with symptoms of depression than earlier or later bedtimes. Kang et al. [40] found that late awakening leads to higher caffeine intake and severe fatigue among Korean male adolescents. Previous research evidence confirmed that bedtime and wake-up times are crucial factors from medical and behavioral health perspectives.

Earlier wake-up and bedtime also decreased the possibility of obesity. Further, later wake-up time was linked to a higher ratio of smoking, and later bedtime was linked to a higher ratio of alcohol consumption. Miller et al. [41] examined alcohol use as a predictor of sleep patterns among college students. Considering the characteristics of adolescents, alcohol consumption as a consequence of late bedtime may have been more suitable. As such, a large body of literature reported that unhealthy sleep patterns were associated with substance use [28,42], and our findings confirmed the previous findings. Helping adolescents go to bed and rise early should be considered important in promoting positive health outcomes and diminishing health risk behaviors.

This study has several limitations. Although the study shed light on the relationship between sleep patterns and health outcomes and health risk behaviors among adolescents, the findings are only representative of adolescents attending school. Adolescents who do not attend school may be inclined to have adverse sleep patterns and more negative health outcomes in less-structured environments. Thus, future research on these adolescents should be conducted. Second, the data relies on self-report leading to a possibility of inaccurate reporting of sleep patterns. One study found that adolescents underestimated their sleep duration by $30 \mathrm{~min}$ [43]. A number of studies also used a self-reported survey questionnaire on sleep patterns [28,41,42,44]. Lastly, smoking and alcohol consumption may have been underestimated because of errors in self-report among adolescents [45,46].

This study contributes to understanding the significant associations between sleep patterns including sleep duration, bedtime, and wake-up time to health outcomes and health risk behaviors. Using a longitudinal approach allowed us to produce valid results. Obesity, the number of chronic symptoms, SRH, smoking, and alcohol consumption were negatively affected by late bedtime as well 
as late wake-up time. Also, inadequate sleep duration influenced obesity and health risk behaviors including smoking and alcohol consumption. Those effects were revealed for both weekdays and weekends, but the effects were stronger for weekdays. The findings from this study indicate that helping adolescents go to bed and rise early and having enough time to sleep should be strongly considered in promoting positive health outcomes and reducing health risk behaviors. Improving parent, teacher and adolescent awareness of the effects of sleep patterns on health is an adequate beginning. Sleep patterns are a core component of medical or behavioral health interventions for decreasing obesity and preventing health risk behaviors.

This study has implications for research in the field of behavioral health. Further research examining sleep patterns and other factors including cognitive abilities, school adjustment, and relationships with family and friends is needed. Also, future research is needed to examine adolescents' factors that may moderate these associations. If we better understand the relationship between sleep patterns and health-related factors, intervention studies designed to improve health status by promoting sleep quality should be conducted for adolescents.

\section{Conclusions}

Significant relationships between sleep patterns and various health-related variables were found among the school-based population of adolescents in Korea. Investigating the longitudinal trajectory of the effects of sleep patterns on health outcomes and health risk behaviors can be a next step to further understand these relationships. Identification of healthy sleep patterns for adolescents is needed.

Author Contributions: Conceptualization, J.K., J.-W.N. and Y.D.K. Methodology, J.K., J.-W.N. and Y.D.K. Formal analysis, J.K. Writing-original draft, J.K., J.-W.N. and A.K. Writing-review \& editing, J.-W.N. and Y.D.K. Supervision, Y.D.K.

Funding: This research received no external funding.

Conflicts of Interest: The authors declare no conflict of interest.

\section{References}

1. National Heart, Lung, and Blood Institute. Sleep Deprivation and Deficiency. 2018. Available online: https://www.nhlbi.nih.gov/health-topics/sleep-deprivation-and-deficiency (accessed on 19 December 2018).

2. Tarokh, L.; Saletin, J.M.; Carskadon, M.A. Sleep in adolescence: Physiology, cognition and mental health. Neurosci. Biobehav. Rev. 2016, 70, 182. [CrossRef]

3. Do, Y.K.; Shin, E.; Bautista, M.A.; Foo, K. The associations between self-reported sleep duration and adolescent health outcomes: What is the role of time spent on Internet use? Sleep Med. 2013, 14, 195-200. [CrossRef]

4. McKnight-Eily, L.R.; Eaton, D.K.; Lowry, R.; Croft, J.B.; Presley-Cantrell, L.; Perry, G.S. Relationships between hours of sleep and health-risk behaviors in US adolescent students. Prev. Med. 2011, 53, 271-2733. [CrossRef]

5. Telzer, E.H.; Fuligni, A.J.; Lieberman, M.D.; Galván, A. The effects of poor quality sleep on brain function and risk taking in adolescence. Neuroimage 2013, 71, 275-283. [CrossRef]

6. Fallone, G.; Owens, J.A.; Deane, J. Sleepiness in children and adolescents: Clinical implications. Sleep Med. Rev. 2002, 6, 287-306. [CrossRef]

7. Wolfson, A.R.; Carskadon, M.A. Understanding adolescent's sleep patterns and school performance: Acritical appraisal. Sleep Med. Rev. 2003, 7, 491-506. [CrossRef]

8. Carskadon, M.A.; Acebo, C.; Jenni, O.G. Regulation of adolescent sleep: Implications for behavior. Ann. N. Y. Acad. Sci. 2004, 1021, 276-291. [CrossRef]

9. Iglowstein, I.; Jenni, O.G.; Molinari, L.; Largo, R.H. Sleep duration from infancy to adolescence: Reference values and generational trends. Pediatrics 2003, 111, 302-307. [CrossRef]

10. Matricciani, L.; Olds, T.; Petkov, J. In search of lost sleep: Secular trends in the sleep time of school-aged children and adolescents. Sleep Med. Rev. 2012, 16, 203-211. [CrossRef]

11. Liu, X.; Uchiyama, M.; Okawa, M.; Kurita, H. Prevalence and correlates of self-reported sleep problems among Chinese adolescents. Sleep 2000, 23, 27-34. [CrossRef] 
12. Andrade, M.M.; Benedito-Silva, A.A.; Menna-Barreto, L. Correlations between morningness-eveningness character, sleep habits and temperature rhythm in adolescents. Braz. J. Med. Biol. Res. 1992, 25, 835-839. [PubMed]

13. Carskadon, M.A. Patterns of sleep and sleepiness in adolescents. Pediatrician 1990, 17, 5-12. [PubMed]

14. Carskadon, M.A.; Vieira, C.; Acebo, C. Association between puberty and delayed phase preference. Sleep 1993, 16, 258-262. [CrossRef] [PubMed]

15. Epstein, R. Sleep habits of children and adolescents in Israel: The influence of starting time of schools. Sleep Res. 1995, 24, 432.

16. Ishihara, K.; Honma, Y.; Miyake, S. Investigation of the children's version of the morningness-eveningness questionnaire with primary and junior high school pupils in Japan. Percep. Mot. Skills 1990, 71, 1353-1354. [CrossRef]

17. Saarenpää-Heikkilä, O.A.; Rintahaka, P.J.; Laippala, P.J.; Koivikko, M.J. Sleep habits and disorders in Finnish schoolchildren. J. Sleep Res. 1995, 4, 173-182. [CrossRef] [PubMed]

18. Owens, J.A.; Weiss, M.R. Insufficient sleep in adolescents: Causes and consequences. Minerva Pediatr. 2017, 69, 326-336. [PubMed]

19. Gregory, A.M.; Sadeh, A. Sleep, emotional and behavioral difficulties in children and adolescents. Sleep Med. Rev. 2012, 16, 129-136. [CrossRef] [PubMed]

20. Pollak, C.P.; Bright, D. Caffeine consumption and weekly sleep patterns in US seventh-, eighth-, and ninth-graders. Pediatrics 2003, 111, 42-46. [CrossRef] [PubMed]

21. Carskadon, M.A. The second decade. In Sleeping and Waking Disorders: Indications and Techniques; Butterworth-Heinemann: Oxford, UK, 1982.

22. Yang, C.K.; Kim, J.K.; Patel, S.R.; Lee, J.H. Age-related changes in sleep/wake patterns among Korean teenagers. Pediatrics 2005, 115, 250-256. [CrossRef]

23. Must, A.; Strauss, R.S. Risks and consequences of childhood and adolescent obesity. Int. J. Obes. Relat. Metab. Disord. 1999, 23, S2-S11. [CrossRef]

24. Patel, S.R.; Hu, F.B. Short sleep duration and weight gain: A systematic review. Obesity 2008, 16, 643-653. [CrossRef]

25. Taveras, E.M.; Gillman, M.W.; Peña, M.M.; Redline, S.; Rifas-Shiman, S.L. Chronic sleep curtailment and adiposity. Pediatrics 2014, 133, 1013-1022. [CrossRef]

26. Taveras, E.M.; Rifas-Shiman, S.L.; Oken, E.; Gunderson, E.P.; Gillman, M.W. Short sleep duration in infancy and risk of childhood overweight. Arch. Pediatr. Adolesc. Med. 2008, 162, 305-311. [CrossRef]

27. Dahl, R.E.; Lewin, D.S. Pathways to adolescent health sleep regulation and behavior. J. Adolesc. Health 2002, 31, 175-184. [CrossRef]

28. Miller, N.L.; Tvaryanas, A.P.; Shattuck, L.G. Accommodating adolescent sleep-wake patterns: The effects of shifting the timing of sleep on training effectiveness. Sleep 2012, 35, 1123-1136. [CrossRef]

29. Wells, J.; Hallal, P.; Reichert, F.; Menezes, A.M.B.; Araújo, C.L.P.; Victora, C.G. Sleep patterns and television viewing in relation to obesity and blood pressure: Evidence from an adolescent Brazilian birth cohort. Int. J. Obes. 2008, 32, 1042-1049. [CrossRef]

30. Hox, J. Multilevel Analysis: Techniques and Applications, 2nd ed.; Routledge: Abingdon, UK, 2010.

31. Martinez, S.M.; Tschann, J.M.; Butte, N.F.; Gregorich, S.E.; Penilla, C.; Flores, E.; Greenspan, L.C.; Pasch, L.A.; Deardorff, J. Short sleep duration is associated with eating more carbohydrates and less dietary fat in Mexican American children. Sleep 2017, 40,1-7. [CrossRef]

32. Nixon, G.M.; Thompson, J.M.D.; Han, D.Y.; Becroft, D.M.; Clark, P.M.; Robinson, E.; Waldie, K.E.; Wild, C.J.; Black, P.N.; Mitchell, E.A. Short sleep duration in middle childhood risk factors and consequences. Sleep 2011, 31, 71-78. [CrossRef]

33. O'Brien, E.M.; Mindell, J.A. Sleep and risk-taking behavior in adolescents. Behav. Sleep Med. 2005, 3, $113-133$. [CrossRef]

34. Sung, V.; Beebe, D.W.; VanDyke, R.; Fenchel, M.C.; Crimmins, N.A.; Kirk, S.; Hiscock, H.; Amin, R.; Wake, M. Does sleep duration predict metabolic risk in obese adolescents attending tertiary services? A cross-sectional study. Sleep 2011, 34, 891-898. [PubMed]

35. Wheaton, A.G.; Chapman, D.P.; Croft, J.B. Self-reported sleep duration and weight-control strategies among US high school students. Sleep 2013, 36, 1139-1145. [CrossRef] [PubMed] 
36. Pasch, K.E.; Latimer, L.A.; Cance, J.D.; Moe, S.G.; Lytle, L.A. Longitudinal bi-directional relationships between sleep and youth substance use. J. Youth Adolesc. 2012, 41, 1184-1196. [CrossRef] [PubMed]

37. Mindell, J.A.; Telofski, L.S.; Wiegand, B.; Kurtz, E.S. A Nightly bedtime routine: Impact on sleep problems in young children and maternal mood. Sleep 2009, 32, 599-606. [CrossRef] [PubMed]

38. Ogi, H.; Nakamura, D.; Ogawa, M.; Nakamura, T.; Izawa, K. Associations between parents' health literacy and sleeping hours in children: A cross-sectional study. Healthcare 2018, 6, 32. [CrossRef] [PubMed]

39. Goh, E. Relationship between sleep timing and depressive mood in Korean adolescents: Based on the Korea Youth Risk Behavior Web-based survey. J. Korean Soc. Sch. Health 2016, 29, 90-97. [CrossRef]

40. Kang, S.H.; Yoo, H.K.; Chung, S.; Kim, C.Y. Eveningness, sleep patterns, daytime sleepiness and fatigue in Korean male adolescents. Sleep Med. Psychophysiol. 2012, 19, 89-96.

41. Miller, M.B.; Van Reen, E.; Barker, D.H.; Roane, B.M.; Borsari, B.; McGeary, J.E.; Seifer, R.; Carskadon, M.A. The impact of sleep and psychiatric symptoms on alcohol consequences among young adults. Addict. Behav. 2017, 66, 138-144. [CrossRef]

42. Campbell, I.G.; Kraus, A.M.; Burright, C.S.; Feinberg, I. Restricting Time in bed in early adolescence reduces both NREM and REM sleep but does not increase slow wave EEG. Sleep 2016, 39, 1663-1670. [CrossRef]

43. Beebe, D.W.; Fallone, G.; Godiwala, N.; Flanigan, M.; Martin, D.; Schaffner, L.; Amin, R. Feasibility and behavioral effects of an at-home multi-night sleep restriction protocol for adolescents. J. Child Psychol. Psychiatry 2008, 49, 915-923. [CrossRef]

44. Wheaton, A.G.; Chapman, D.P.; Croft, J.B. School start times, sleep, behavioral, health, and academic outcomes: A review of the literature. J. Sch. Health 2016, 86, 363-381. [CrossRef] [PubMed]

45. Engels, R.C.; Knibbe, R.A.; Drop, M.J. Inconsistencies in adolescents' self-reports of initiation of alcohol and tobacco use. Addict. Behav. 1997, 22, 613-623. [CrossRef]

46. Brener, N.D.; Billy, J.O.; Grady, W.R. Assessment of factors affecting the validity of self-reported health-risk behavior among adolescents: Evidence from the scientific literature. J. Adolesc. Health 2003, 33, 436-457. [CrossRef]

(C) 2019 by the authors. Licensee MDPI, Basel, Switzerland. This article is an open access article distributed under the terms and conditions of the Creative Commons Attribution (CC BY) license (http://creativecommons.org/licenses/by/4.0/). 